\title{
Asymmetrical mini disk tools - possibilities of use and directions for further development
}

\author{
Krzysztof Kotwica \\ AGH University of Science and Technology, Poland
}

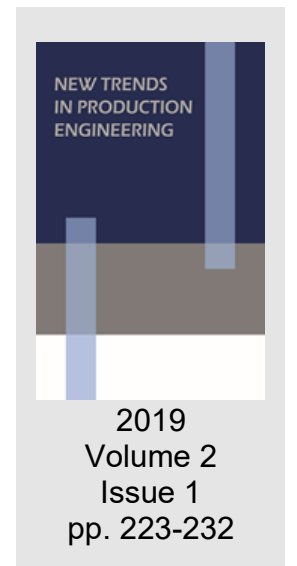

Date of submission to the Editor: 05/2019

Date of acceptance by the Editor: 07/2019

\section{INTRODUCTION}

In underground mining industry, both in Poland and in the world, most of the galleries or tunnels are drilled with mechanical methods - applying arm road headers. It allows you to obtain large mining capacity or drilling speed, but also generates a number of hazards or restrictions, depending of used mining tools. But mining hard and very hard rocks, using the current cutting tools and mining heads, is becoming less and less effective. It is related mainly to small-cutting advance rate, so the cutting process became economically ineffective. No less important factor is the content of minerals and inclusions in the rocks, causing rapid abrasion and wear of mining cutting tools and in the case of inclusions, for example spherosiderites, the occurrence of sparks during mining process. Especially during coal galleries face excavation in underground coal mines, ignition of methane is possible and gas explosion (Prostański, 2017).

The second of the most commonly used methods in the process of mechanical mining of hard rocks is mining by means of static crushing, carried out with the help of wheel tools called disks. Disk tools used for this mining method can be symmetrical or asymmetric.

The symmetrical disk is cutting the rock by static crumpling. The typical construction of disk tool consists of shaft, seal, hub, split ring and replaceable cutting ring. There are three types of symmetric disk tools: smooth disks, disks armed with carbide insert and toothed discs, in one and double or even triple blades versions. However, the first two types are most often used, which in the view are shown in Figure 1. Their diameters can be even up to $500 \mathrm{~mm}$ (Kotwica, 2019). The ability to rotate the tool in the head reduces the friction forces, which reduces energy loss and generates less toll edge wear and dustiness, compared to cutting tools. In addition, the rotation of the cutting disc causes short contact of the edge section with the rock, which greatly facilitates the removal of heat emitted on the edge of the disk and ensures very long durability of the tool.

These symmetrical disks are used in Full-Diameter TBM miners, shield or gripper type. 


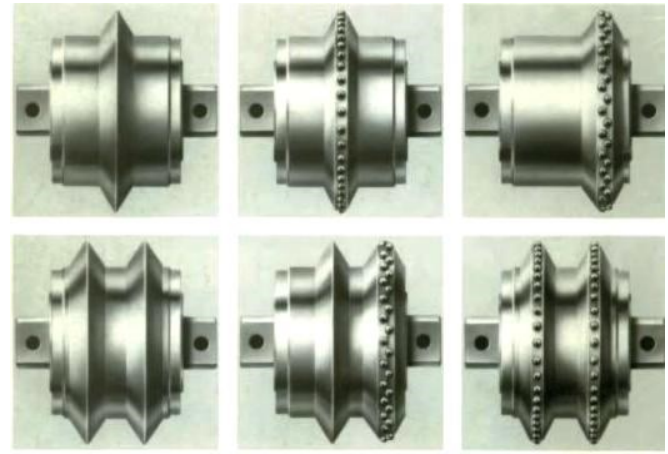

Fig. 1 View of smooth disk and disk armed with carbide insert in one and double blades versions Source: (Kotwica, 2019)

Smooth single blade disk tool can works without visible wear even up to few kilometers of roadway or tunnel advance. In comparison cutting tool lifetime is not more than several cubic meter of wining per piece. It allows also to get large daily advance of tunnel up to 80 meters.

But it need in the case of a large number of disk tools on the mining head a very large value of the total pressure force (depending on the diameter of the body up to $25000 \mathrm{kN}$ ) and many times more value of side expanded force to ensure the stability of TBM work.

The occurrence of large values of reaction forces occures large mass (up to $3500 \mathrm{Mg}$ ) and dimensions of the machine (the length of the TBM reaching up to 400 meters). This results in the limited use of this type of machinery for the drilling of excavations with a very large runnout, where very large costs related to their production and construction in the mining excavation can be paid back (Kotwica, 2019).

A clear drawback of the static crumpling method is necessity to provide large pressure forces to the disks. Whereas, asymmetrical disk tools have been used first as mining tools for longwall shearers to increase output of a large size grains. Conducted industrial tests demonstrated usefulness of such equipment for obtaining higher product graining. Asymmetrical disk tools are applied in the technique of mechanical mining not only as crushing devices but also in the undercutting method (Bołoz, 2018). The principle of this method is mining a rock by its cutting off towards a free space. A disk tool affects the rock tangentially to the surface of the mined body, similarly as for cutting tools, but the difference is that here it uses the disk rolling movement which efficiently eliminates sliding friction in favor of rolling friction. Figure 2 presents a diagram of mining with this method (Weber, 1994).

Application of disk tools in that way lowers energy consumption and pressure force. It allows designing mining machines with respectively lower energy demands and lower requirements concerning stability than in case of machines equipped with classical disks, operating perpendicularly towards the surface of a mined body (Weber, 1994). In the case of this method, however, there are strongly varying lateral forces on the edges of disk tools. This is the reason for the difficulty in properly taking over the reaction on the disk tool holders and their bearing. 


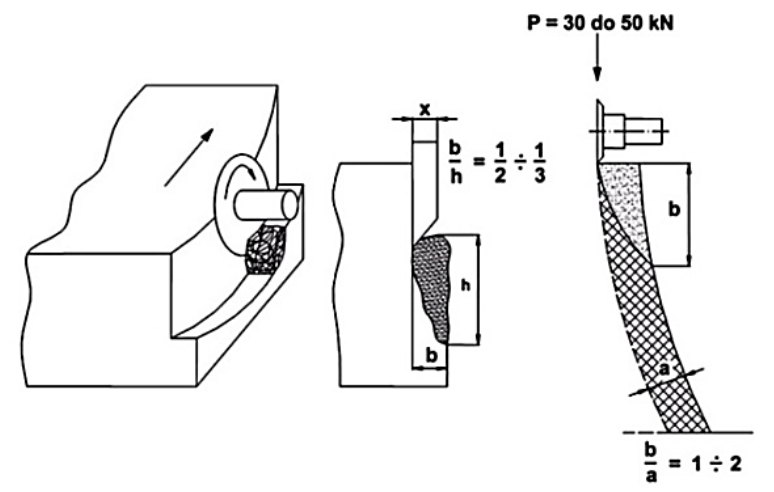

Fig. 2 Diagram of the undercutting method mining principle

Source: (Weber, 1994)

The initial research of a machine developed by Wirth, using this method, equipped with four swinging and rotating arms gave positive results (Weber, 1994). The view of the Wirth machine used undercutting method and the effects of its work is shown in Figure 3.
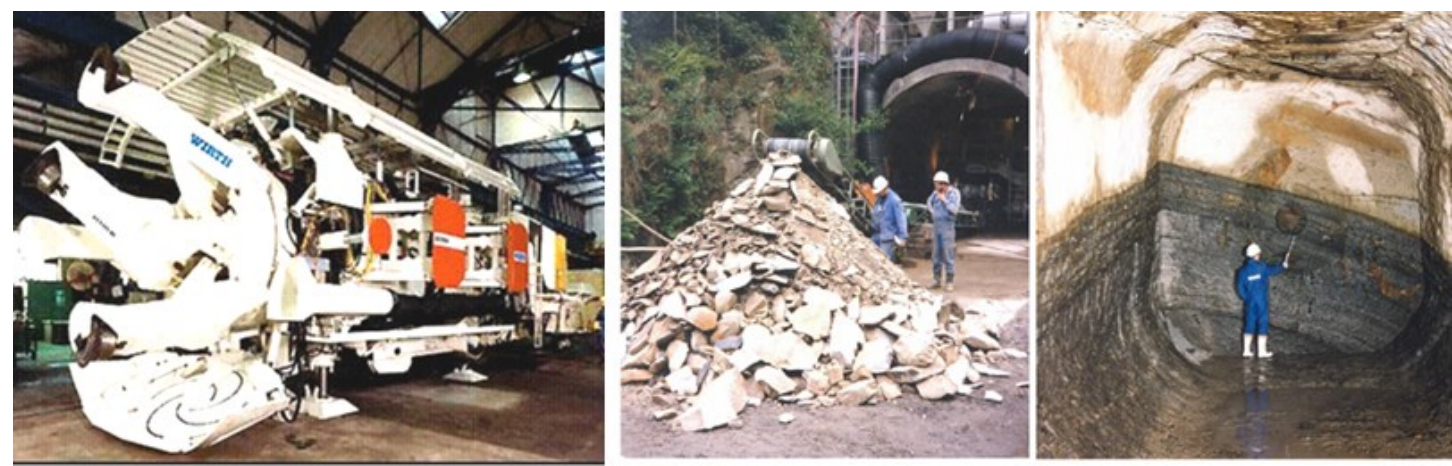

Fig. 3 The view of the Wirth machine used undercutting method and the effects of its work Source: (Weber, 1994)

There were other concepts of use on the mining heads mainly asymmetrical disks, in which the basic idea was to use the disk as a chipping tool. Thanks to this, energy consumption and the value of the pressure force are smaller, which gives the possibility of constructing a mining machine with lower energy parameters, smaller requirements due to stability criterion, as in the case of classic disks operating perpendicular to the rock surface. In the case of machines using this technique, inter alia, by Aker Wirth and Atlas Copco, this method showed full usefulness (Kotwica, 2019). There were also concepts of another tools developed, so called fishing tools with magnetic systems (Romanyshyn et al., 2017), but there can be used mainly for drilling.

The benefits of hard rock mining using disk tools were the reason to develop new solutions of mining tools and rock mining techniques in AGH University of Science and Technology in Krakow. The new solutions of mining asymmetrical mini disk tools were developed and successful investigation of rock mining techniques with use of these tools and mining heads has been performed. These mining tools and heads were designed especially for road headers. The results of performed laboratory and industrial researches are described below. 


\section{POSSIBILITIES OF MINI DISK TOOLS APPLICATION}

For many years, work has been carried out on the development of new construction solutions for mining heads of road headers or mining methods that allow effective mining of hardly workable rocks. One of such solutions is a mining head, developed and tested at the Colorado School of Mines (Kotwica, 2019). To reduce the values of mining forces, symmetrical mini-discs with a diameter of $125 \mathrm{~mm}$ were used. The biggest problem is the bearing of disks, connected with their heavy load. Several solutions for the bearing of tools and a technical design of the body were developed, on the basis of which the prototype was made. The mining head model, along with the arrangement diagram of the tools on its surface, is shown in Figure 4. The results of the trials were satisfactory, but no detailed data on this subject.

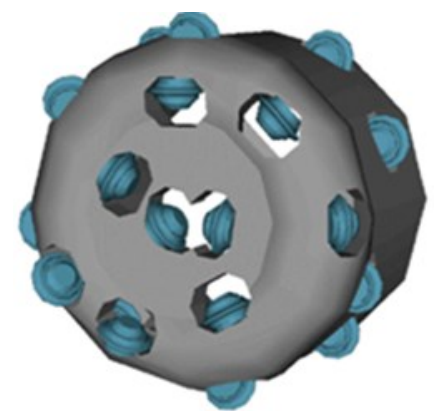

Fig. 4 Spatial model of mining head with symmetrical mini disk tools Source: (Kotwica, 2019)

In AGH University of Science and Technology, an attempt was also undertaken to work out a solution of a mining unit equipped with mini disk tools, mounted directly on the head body. Due to high load of the disk tools and low effectiveness of mining, this solution was given up.

An the basis of thorough analysis of the world technique condition and results of own tests of rocks mining with asymmetrical disk tools (of diameter up to 160 $\mathrm{mm}$ ) new solution of mining head was proposed. Disk tools were mounted on separate plates that could rotate on the mining head body, and are propelled independently from i (Gospodarczyk et al., 2013). The motion of tools was forced, and caused mining of a rock body with tools along complex movement trajectory. It allows crossing of mining lines of individual disk tools, and facilitates mining compact rocks through breaking off rock furrows. It should lower energy consumption of the process. Estimating the parameter values for special solution of mining head design through theoretical simulation was very complicated or in some cases even impossible. That is why tests of compact rock mining with disk tools on a specially constructed lab stand were suggested. Lab tests of the mining process were planned to be performed only for one plate with asymmetrical disk tools of diameter $160 \mathrm{~mm}$ and edge angle of $40^{\circ}$. The max diameter of the plate was defined at $450 \mathrm{~mm}$ and the number of disc tools at 6 pieces. The special laboratory stand was designed and implemented for examining the process of compact rock mining with asymmetrical mini disk tools. A model of the stand is shown in Figure $5 \mathrm{~A}$. 
It was planned to perform tests comprising at least four changing parameters: direction and number of rotations of the plate (overshot and undershot) rotations and at least three ranges of rotation velocity 40,50 , and $60 \mathrm{rpm}$ ), cutting spacing (from $10 \mathrm{~mm}$ to $40 \mathrm{~mm}$ ), and cutting depth (at least three values of cutting depth from 6 to $20 \mathrm{~mm}$ ).

A
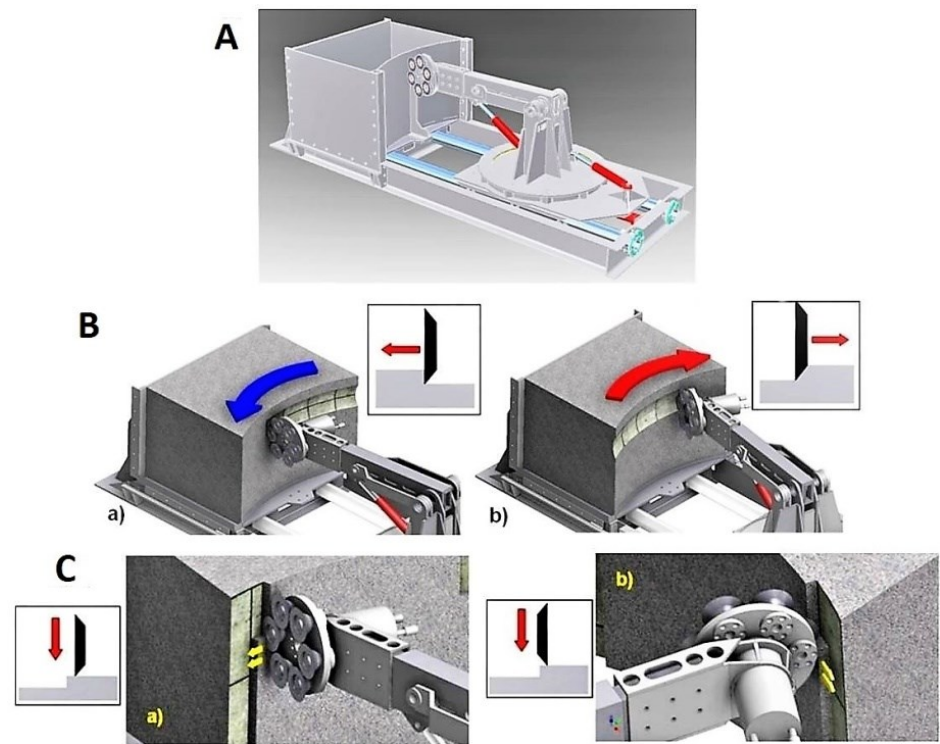

Fig. 5 The lab stand for testing mining process of compact rocks with disk tools of complex trajectory: A - model of a lab stand,

B - diagram of horizontal mining of the samples: a) to the left, b) to the right,

C - diagram of vertical mining of the sample: a) from the left edge, b) from the right edge Source: (Gospodarczyk et al., 2013)

For above listed parameters it was assumed to perform cuts, moving the plate horizontally and then vertically, in relation to the rock sample. A diagram of the rock mining in both planes is presented in Figures 5B and $\mathrm{C}$. Depending on mining direction: left - right and top - down, the disk tools attack the rock body with its flat or inclined surface (Gospodarczyk et al., 2013).

The tests were conducted on a pure concrete sample, with uniaxial compressive strength of $26 \mathrm{MPa}$. Measurements of the obtained output allowed to conclude that as a result of vertical mining the dominant fraction were grains several times bigger than grains obtained during horizontal mining, which is presented in Figure 6. In the case of mining in vertical plane, the rock was chipped off, typical for undercutting method. During the mining in horizontal plane, plate with disk tools mined the rock in a process similar to milling.

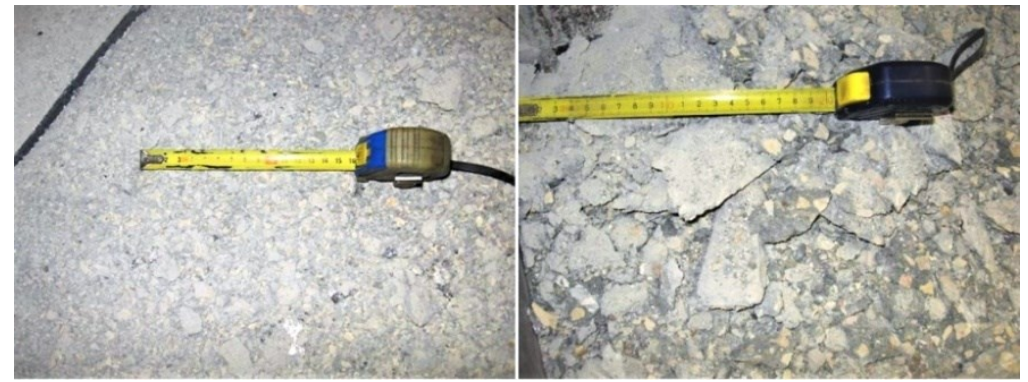

Fig. 6 The output graining obtained during horizontal (left) and vertical (right) mining Source: (Gospodarczyk et a.l, 2013) 
Another set of tests was performed for sample mining from the right and left side. The tests were conducted at the depth of $\mathrm{g}=15$ and $20 \mathrm{~mm}$, with spacing $t=20,30$ and $40 \mathrm{~mm}$. It was observed that for each case of mining there was a complete rock chip breakage.

Figure 7 presents mean values of component forces calculated during left and right mining of the sample at depth $\mathrm{g}=15 \mathrm{~mm}$. Mining from the right side was more favourable.
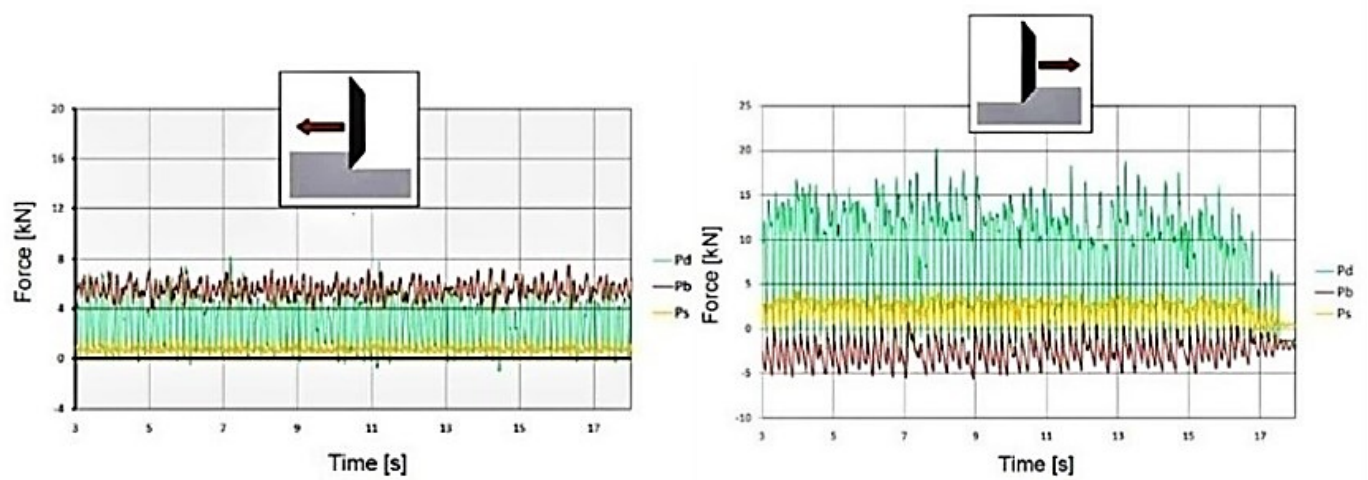

Fig. 7 Diagrams of force values: pressure $P_{d}$, cutting $P_{s}$ and side $P_{b}$, Source: (Gospodarczyk et a.l, 2013) during mining to the left and right at depth of $g=15 \mathrm{~mm}$

The above results were obtained for one design solution of a smooth disk - 160 $\mathrm{mm}$ in diameter and $40^{\circ}$ edge angle. Performing tests for other solutions of disk tools was associated with very high costs and a long time of their execution. That was proposed to perform them on the modernized test stand for single tool testing. The stand was equipped with a mining unit with plate with six disk and a three-axis sensor of forces and moments type CL 16. Three sets of disk tool diameters were selected for the tests: 150,160 and $170 \mathrm{~mm}$, all with a $40^{\circ}$ edge angle, and three sets of disks with different edge angles: $35^{\circ}, 40^{\circ}$ and $45^{\circ}$ with a diameter of $160 \mathrm{~mm}$. Each set consisted of six tools, each of which has been accurately measured and scanned before testing.

It was assumed that each set of disk tools would mined a constant and comparable volume of output equal to about $2 / 3$ of the volume of the sample being cut. The state of the tools before and after the mining process was confronted, allowing comparison of the wear of various types of disk tools. In the measurement process, the 3D scanning technique was used by the HDI Radwance scanner from LMI Technology.

Six cylindrical concrete samples were made for testing. The concrete mix had a compressive strength $\mathrm{R}_{\mathrm{c}}$ of $80 \mathrm{MPa}$. The view of the modernized test stand and the mining test for one of the disk tool sets is shown in Figure 8. The concrete sample was successively mined with layers from the top to down, from the outside to the center of the sample.

Based on the obtained results, it can be concluded that the disks with the largest diameter showed the largest reduction of the outside diameter, while the smallest loss showed disks with the smallest diameter. 
This dependence is approximately square. Also, the increase in the diameter of the central hole of the disk, which cooperates with the fastening shaft, was greatest for the largest diameter disks.
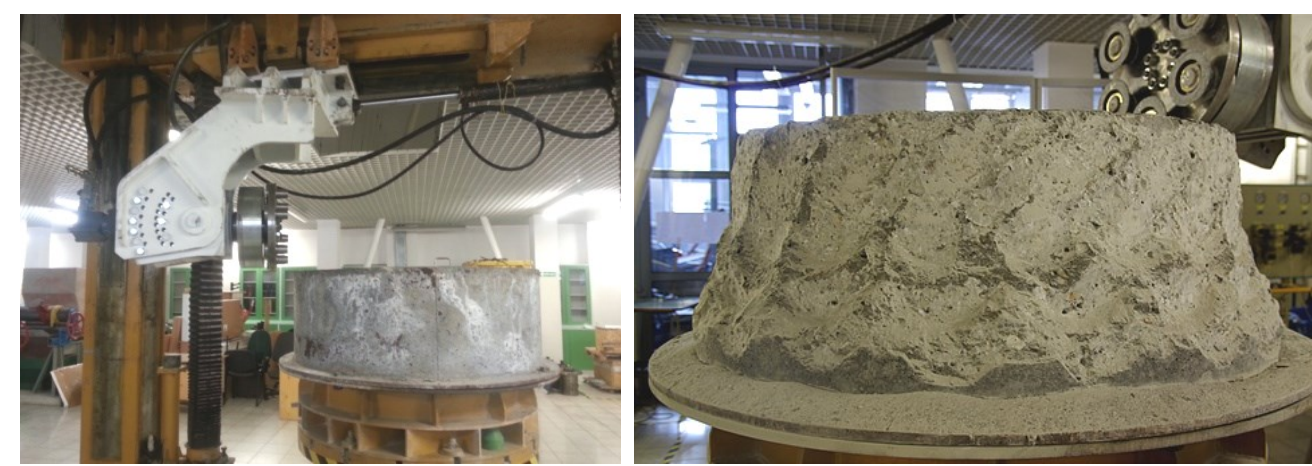

Fig. 8 The view of modernized test stand and view of mining test for one of the disk tool sets Source: (Kotwica et al. 2017)

When comparing disks with variable edge geometry, it can be observed that the disks with the smallest edge angle $\left(35^{\circ}\right)$ weared the fastest, while the smallest wear showed disks with the largest edge angle. An interesting observation is the fact that all disks had a tendency to oval the edge - the radius of the disk rounding increased from the initial $2 \mathrm{~mm}$ to an average of $7.5 \mathrm{~mm}$. In addition, for all disks during the mining, the angle of the edge increased to 90 degrees. The obtained results were basis for developing of new solution of mining head for road headers, with complex motion trajectory of the disk tools. Scheme and kinematic capabilities of the new head mounted on the road header KR 150 are shown in Figure 9.

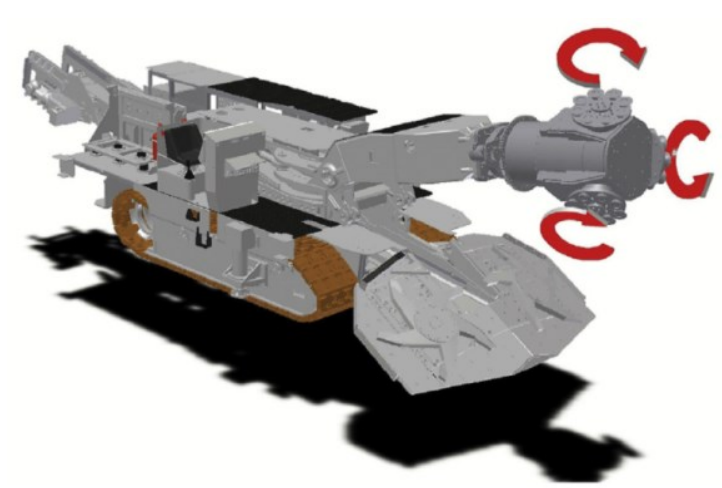

Fig. 9 Scheme and kinematic capabilities of the new head mounted

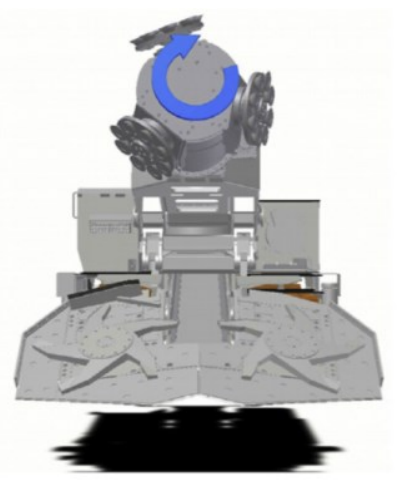
on the roadheader KR 150

Source: (Gospodarczyk et al., 2013)

\section{RESULTS OF FIELD TESTS WITH ASSYMETRICAL MINI DISKS}

The tests were performed on artificial large size concrete block of uniaxial compressive strength of about 40 up to 80 MPa prepared at REMAG Company using new solution of mining head mounted at FR250 road header. The view of this road header and special mining head during the trials is shown in Figure 10. The disk tools were mounted on the plates so that their axis of rotation was tilted inwards by an angle of $-5^{\circ}$. 

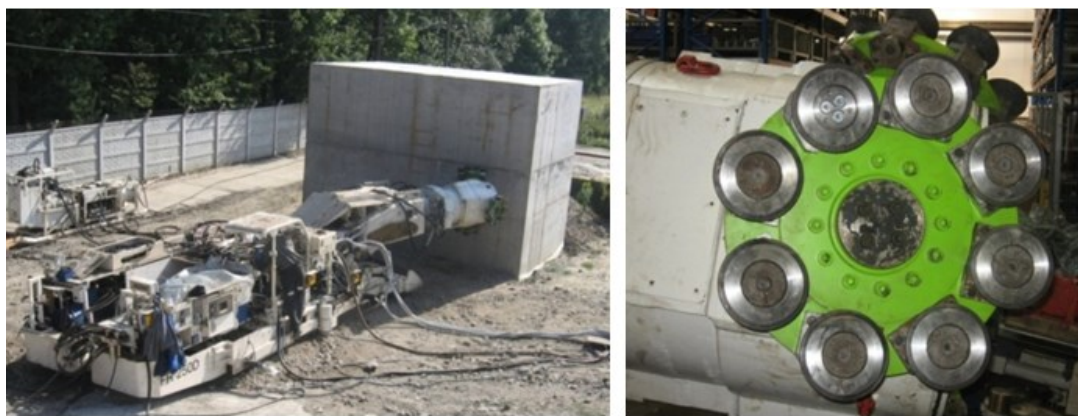

Fig. 10 A view of FR250 road header with mining head with disk tools

The attempts to excavate the block with disk tools mounted at $45^{\circ}$ and $90^{\circ}$ to the surface of the plate surface ended with a quick and catastrophic wear of the tool.

The attempts to replace a disk tool with a smooth wedge by another, reinforced with sintered carbide inserts, have been also unsuccessful. The inserts were broken after few minutes of the work (Kotwica et al., 2017). The view of the new solution of disc tools reinforced with sintered carbide inserts and view of traces of carbide inserts breakage is shown in Figure 11.

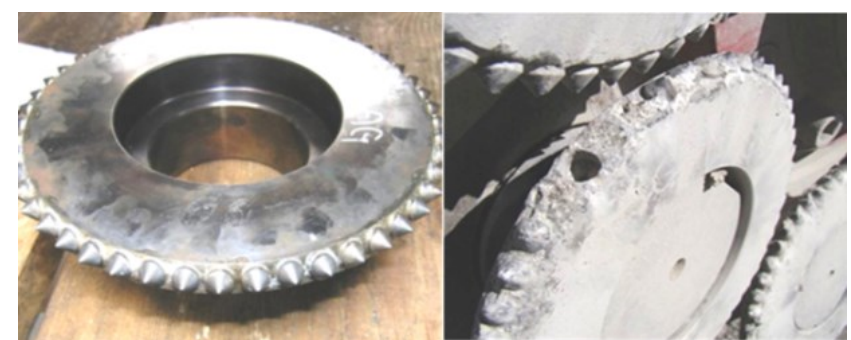

Fig. 11 View of disk tool reinforced with sintered carbide inserts and traces of carbide inserts breakage

Source: (Kotwica et al., 2017)

During the tests, using disk tools made of different materials and by various methods, the efficiency of mining was checked. Disk tools had the same diameter $-170 \mathrm{~mm}$ and wedge angle of $45^{\circ}$. They were made of tool steel, Hadfield or low-alloyed (GS42CrMo4) cast steel and ADI spheroidal cast iron. The tools manufactured from tool steel type NZ3 were full-hardened, to a hardness of over $55 \mathrm{HRC}$. The tools manufactured from tool steel type 36HNM were surface- hardened and tempered. Tools made of cast steel and cast iron were machined after casting. After this mechanical treatment, it was noticed that especially tools made of cast steel had numerous castings defects - blisters and pores. These tools, shown in Figure 12, have been disqualified.

During concrete block mining with larger cutting depth, the best results were obtained for tools made from tool steel type $36 \mathrm{HNM}$. After one hour operation there were not significant traces of wear observed. In the case of disk tolls made from tool steel NZ3, already after very short work numerous edge breaks as well as cracking and breakage of the part of tools were noticed.

However, in the case of disk tools made of ADI cast iron, no breakage of the tool edge but its systematic abrasive wear was observed. 


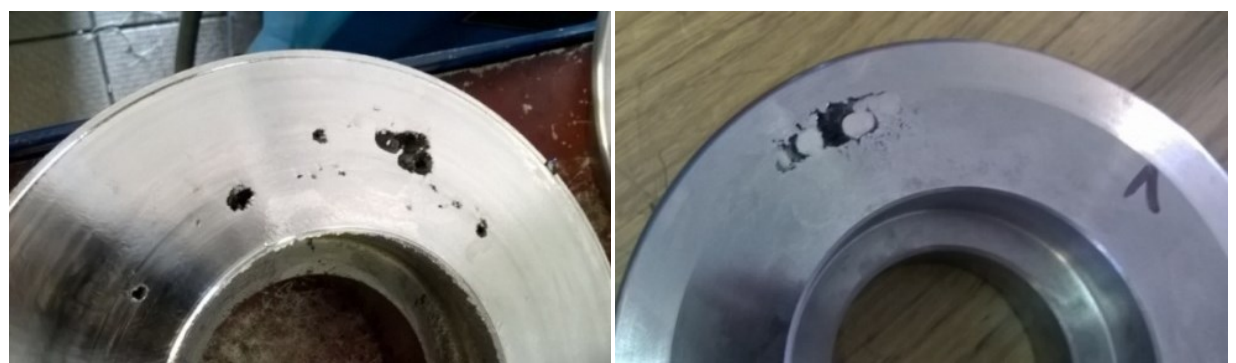

Fig. 12 A view of defective copies of disk tools made of cast steel Source: (Kotwica et al., 2018)

The outside diameter of cast iron tools after about 30 minutes of work was decreased to value of about $135-140 \mathrm{~mm}$. This diameter value did not allow further work. The wear view of tools made from tool steel NZ3 and ADI type cast iron is shown in Figure 13. The reason of quick tools wear was probably to large cutting depth and movement speed of mining head. Combination of both of these parameters caused a heavy load on the tools.

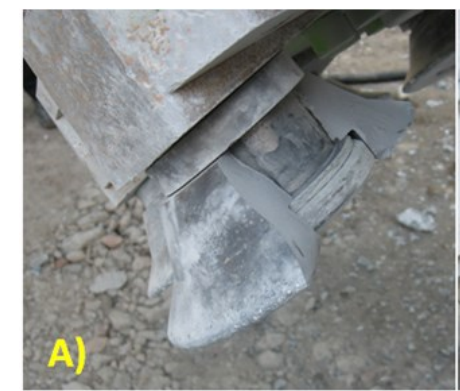

Fig. 13 A view of disk tool wear:

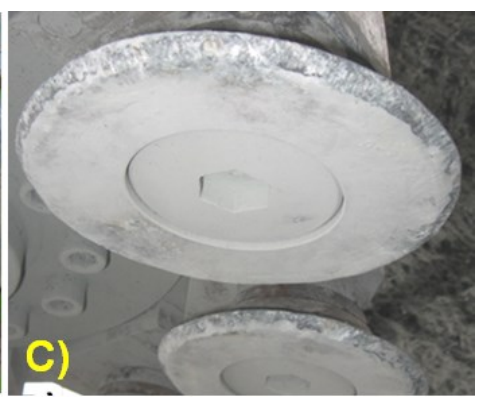

made from steel type $36 \mathrm{HNM}$

\section{CONCLUSION}

As of today, attempts to use mini disk tools (up to $180 \mathrm{~mm}$ in diameter) on the road headers mining heads offer promising results. The suggested solution of asymmetrical disk tools for mining head with tools of complex motion trajectory proved its usefulness while compact rocks mining, and can be used as an alternative for existing mining heads of road headers. But it is necessary to develop and implement a solution of abrasion and impact load resistant disk tools.

In order to extend the life time of disc tools, more attention should be paid to the way they are made and to the material from which they are made and heat treatment. Perhaps the factor that improves the durability of disk tools is the use of casting or forging technology.

It is very important to choose non-symmetrical disc tools with appropriate construction and material parameters. Disk tools with an outer diameter of 170 $\mathrm{mm}$ and smaller, made by machining from tool or construction steels and through-hardened, are not used for the proposed version of the mining head. They are damaged after short-term work. A much better solution are tools made of alloy steels and heat-treated, with additional welding of the edge making the material hard to abrasive. Their durability was definitely higher. 
The Cambridge Engineering Selector Edu Pack, developed by Mike Ashby and David Cebon, can be used to determine the materials for disk tools (Kotwica et al., 2018). The program uses a comprehensive database. By using the program you can get a complete set of information on mechanical, optical, thermal and electrical properties practically for almost every material. Additionally, information about resistance to harmful environmental factors, typical applications, usefulness of heat treatment methods and their further processing is provided.

Another problem occurring during the laboratory tests was the significant blunting of the edges of the disc blades. In order to reduce this phenomenon, these edges should have appropriate rounding - according to the obtained test results even up to $5-8 \mathrm{~mm}$.

\section{REFERENCES}

Bołoz $Ł$, (2018). Model tests of longwall shearer with string feed system, Archives of Mining Sciences, vol. 63 no 1, pp. 61-74,

Gospodarczyk P., Kotwica K., Stopka G., (2013). A new generation mining head with head with disc tool of complex trajectory. Archives of Mining Sciences. Vol. 58, 4. pp. 9851006 ,

Kotwica K (2019) Hard rock mining - cutting or disk tools. IOP Conference Series: Materials Science and Engineering. IMTech Scientific and Technical Conference, [online] Available at: https://iopscience.iop.org/article/10.1088/1757899X/545/1/012019 [Accessed 24 June 2019]. doi:10.1088/1757$899 \times / 545 / 1 / 012019$

Kotwica K et al. (2018) Wybrane problemy urabiania, transportu i przeróbki skał trudnourabialnych, Part 3. Wydawnictwa AGH, Kraków. (in polish)

Kotwica K, et al. (2017) Wybrane problemy urabiania, transportu i przeróbki skał trudnourabialnych, Part 2. Wydawnictwa AGH, Kraków. (in polish)

Kotwica K. (2018). Atypical and innovative tool, holder and mining head designed for roadheaders used to tunnel and gallery drilling in hard rock. Tunnelling and Underground Space Technology, 82, pp. 493-503.

Prostański D., (2017). Empirical models of zones protecting against coal dust explosion. Archives of Mining Sciences. Vol. 62, 2, pp. 611-619,

Romanyshyn T., Dzhus A., Romanyshyn L. (2017). Design and research of fishing tools with national parameters of magnetic systems. Eastern-European Journal of Enterprise Technologies, 88(4/5), pp. 17-22.

Weber W., (1994). Drążenie chodników przy pomocy techniki tylnego wycinania. Maszyna firmy Wirth-HDRK "Continuous Mining Machine". Sympozjum "Drążenie chodników w górnictwie węgla kamiennego", Siemianowice Śl, (in polish)

\footnotetext{
Abstract.

The paper presents a new solution of asymmetrical mini disk tools for mining head of roadheader designed for hard and very hard rock mining. In the first part the benefits of disk tools used in TBM's and special tunneling machines were presented. Next part presents the results of works and laboratory tests performed for developing of new solution of asymmetrical mini disk tools. On the basis of these results new mining head equipped with mini disk tools with a complex trajectory was designed. The results of field tests with different constructional and material solutions of asymmetrical mini disk tools were presented. The directions for further development were described.
}

Keywords: hard rock, mechanical mining, disk tool, tool wear, efficiency 